\title{
From Penrith to Paris (extracts)
}

\section{Katherine Elizabeth Clay}
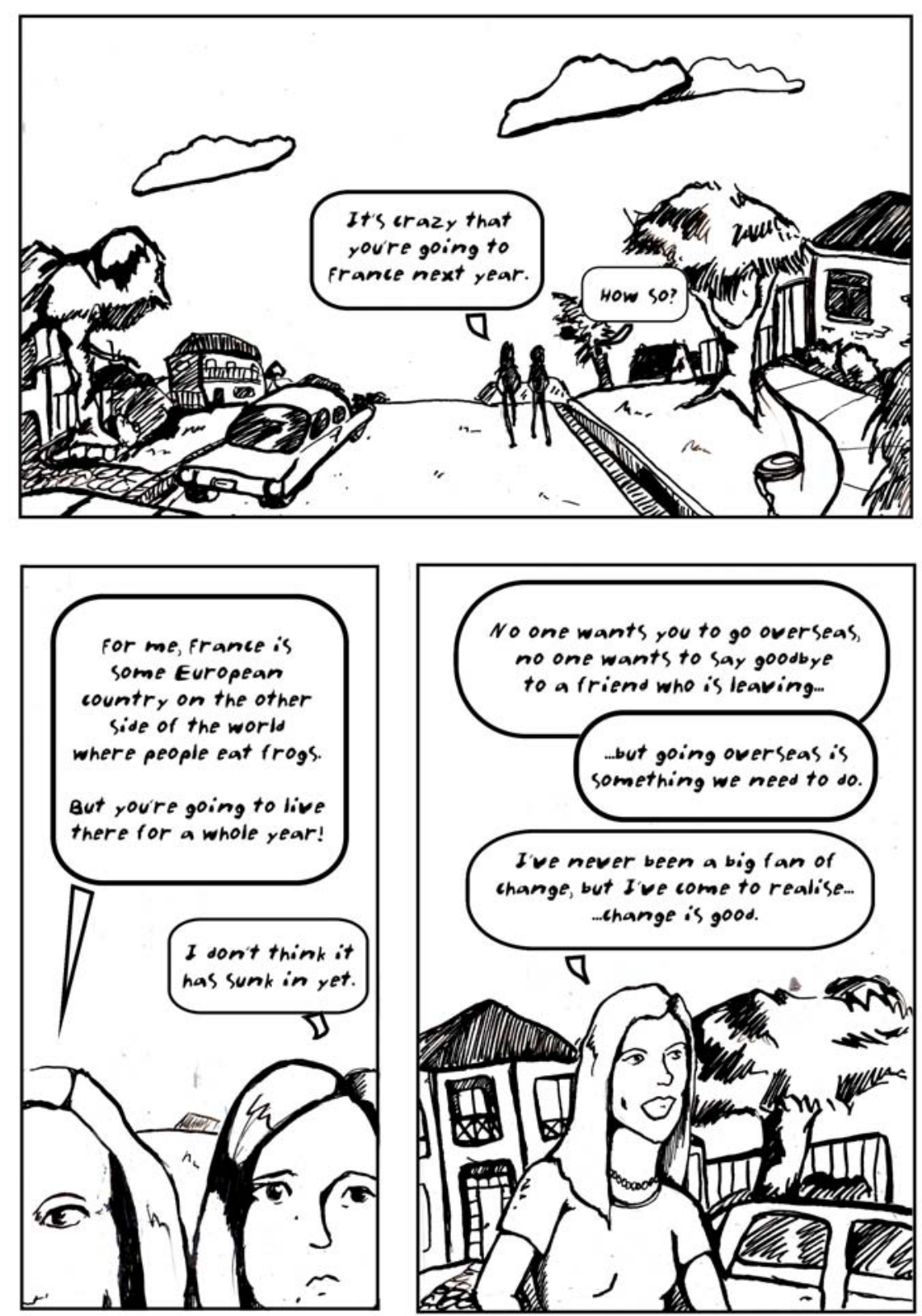

PORTAL Journal of Multidisciplinary International Studies Vol. 3, no. 2 July 2006 ISSN: 1449-2490

http://epress.lib.uts.edu.au/ojs/index.php/portal 


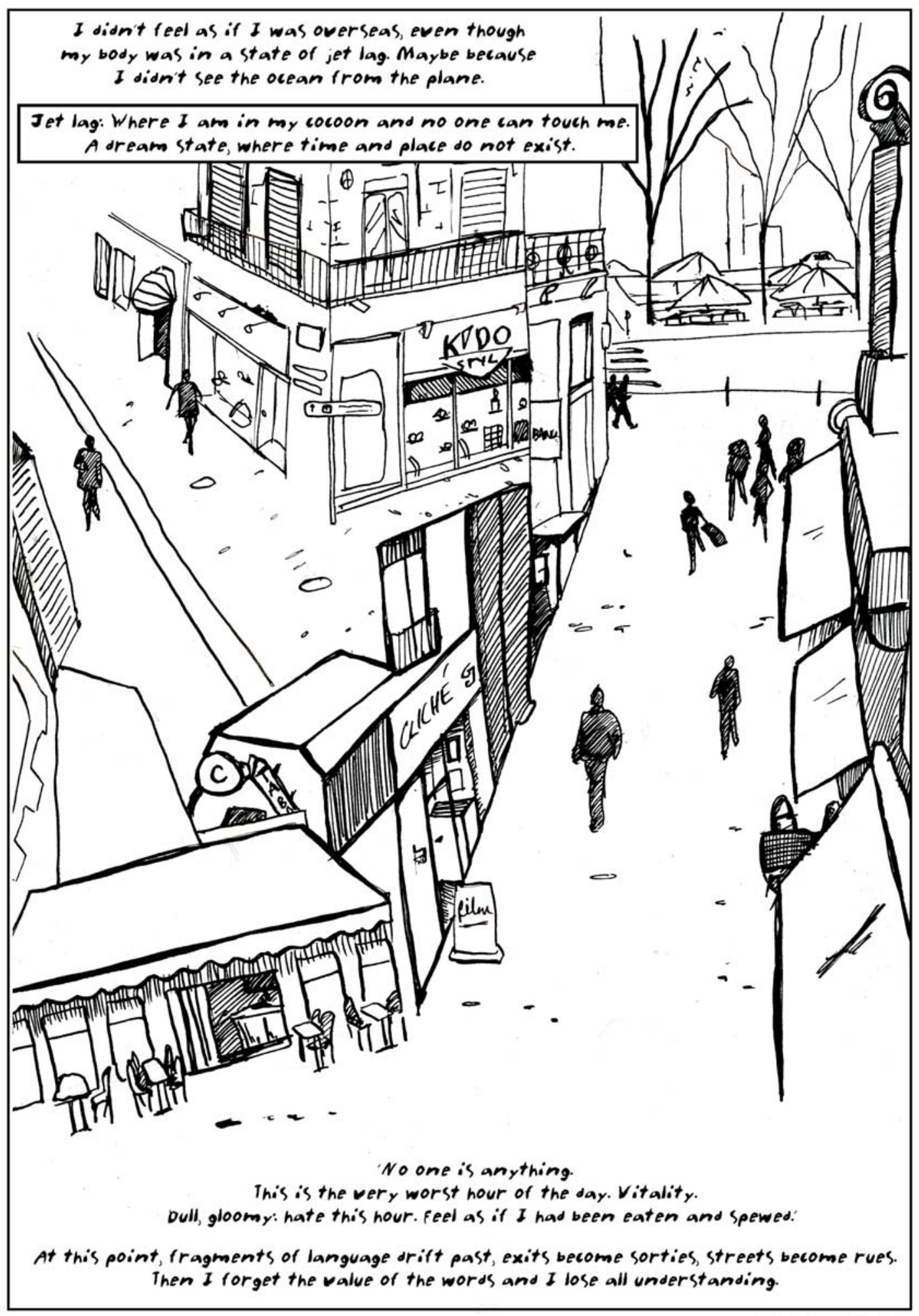

James Joyce, Viysses. 


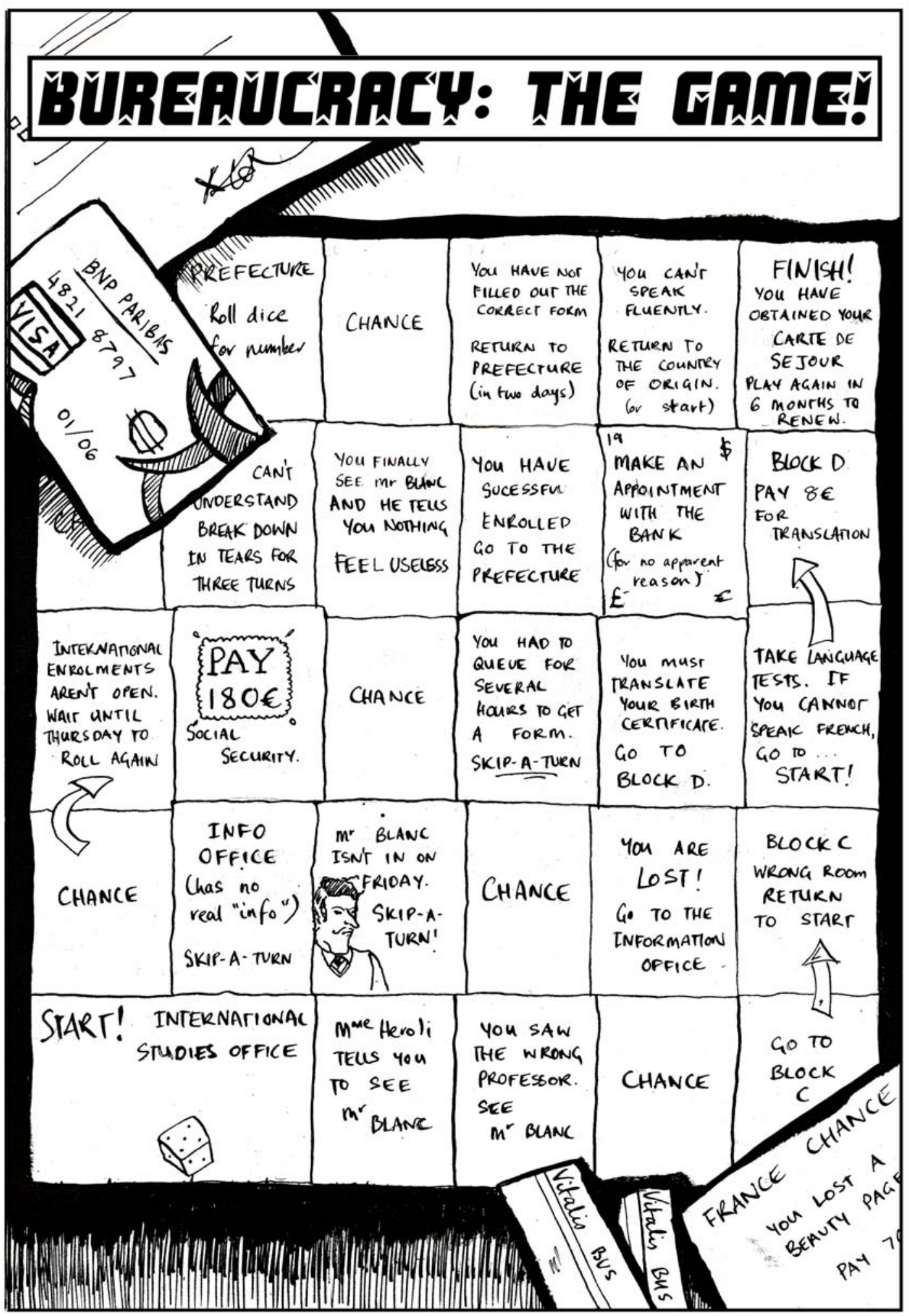



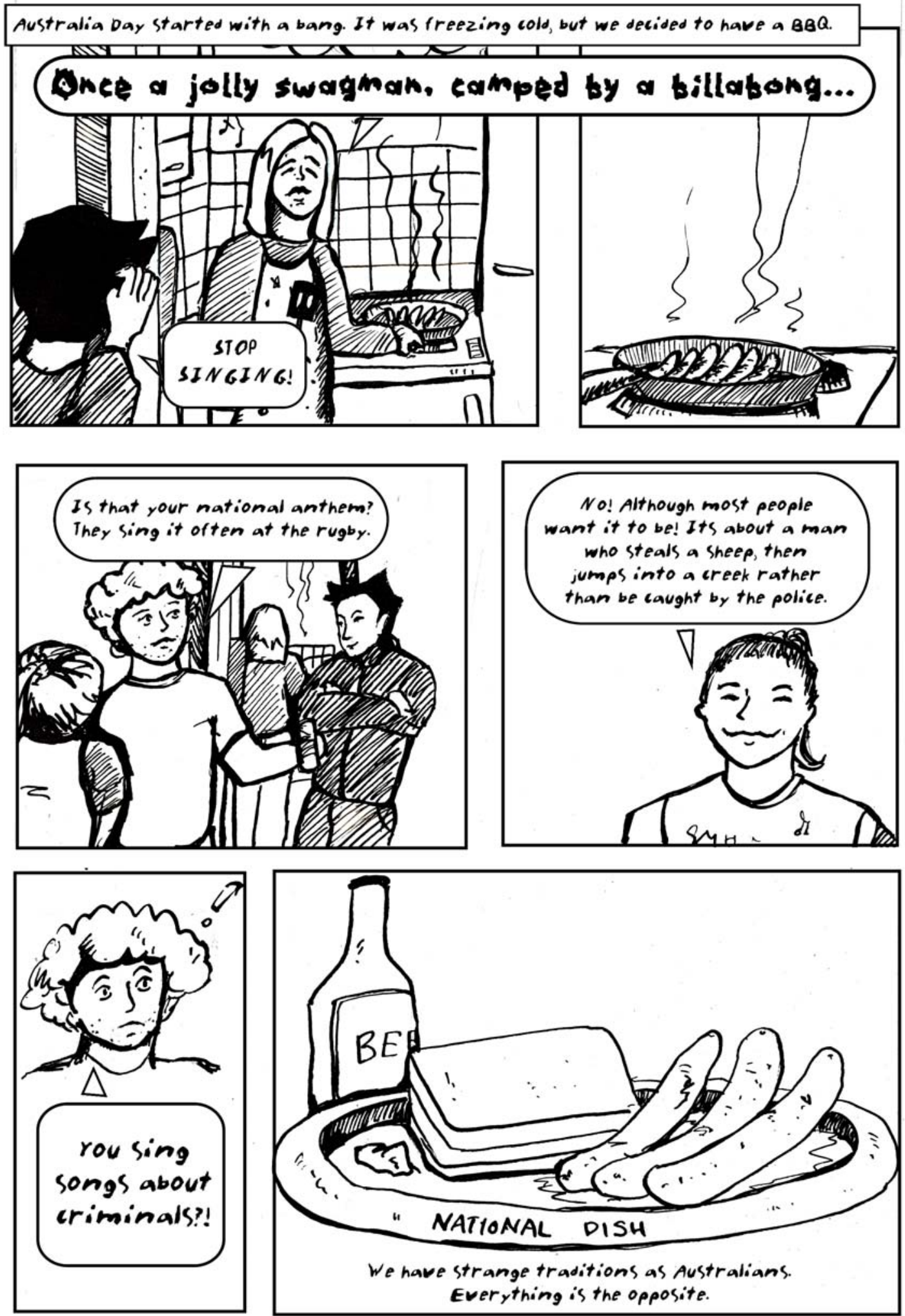